\title{
Synthesis of Copper Nanoparticles Using Mixture of Allylamine and Polyallylamine
}

\author{
Rubén Sierra-Ávila, Marissa Pérez-Alvarez, \\ Gregorio Cadenas-Pliego, Víctor Comparán Padilla, Carlos Ávila-Orta, \\ Odilia Pérez Camacho, Enrique Jiménez-Regalado, \\ Ernesto Hernández-Hernández, and Rosa Martha Jiménez-Barrera
}

Centro de Investigación en Química Aplicada, 25294 Saltillo, COAH, Mexico

Correspondence should be addressed to Marissa Pérez-Alvarez; pamarissa@hotmail.com and Gregorio Cadenas-Pliego; gregorio.cadenas@ciqa.edu.mx

Received 4 February 2015; Accepted 28 March 2015

Academic Editor: Joydeep Dutta

Copyright (C) 2015 Rubén Sierra-Ávila et al. This is an open access article distributed under the Creative Commons Attribution License, which permits unrestricted use, distribution, and reproduction in any medium, provided the original work is properly cited.

Copper nanoparticles (Cu-NPs) with sizes lower than $31 \mathrm{~nm}$ were prepared by wet chemical reduction using copper sulfate solution, hydrazine, and mixture of allylamine (AAm) and polyallylamine (PAAm) as stabilizing agents. The use of AAm/PAAm mixture leads to the formation of $\mathrm{Cu}$ and $\mathrm{CuO}$ nanoparticles. The resulting nanostructures were characterized by XRD, TGA, and TEM. The average particle diameters were determined by the Debye-Scherrer equation. Analysis by TGA, TEM, GS-MS, and ${ }^{1}$ HNMR reveals that synthesized NPs with AAm presented a coating with similar characteristics to NPs with PAAm, suggesting that AAm underwent polymerization during the synthesis. The synthesis of NPs using AAm could be a good alternative to reduce production costs.

\section{Introduction}

In recent years, nanoparticles have received much attention in the scientific community and industry due to their unique physicochemical properties attributed to their relatively small size and high surface area-to-volume ratio $[1,2]$. In particular, copper nanoparticles $(\mathrm{Cu}-\mathrm{NPs})$ are of great interest because of their distinctive catalytic, optical, thermal, magnetic, antimicrobial, electronic, and electrical conducting properties [3-9]. They present a wide range of potential applications in nanotechnology including catalysts [3], additives for lubricants [10], heat transfer nanofluids [11], manufacture of electronic and optical devices [12], conductive inks [13], materials for solar energy conversion [14], biosensors [15], antibiofouling agents [16], and cancer cell treatments [17]. Moreover, copper nanoparticles can be a promising candidate to replace expensive noble metal nanoparticles such as silver and gold [18-20].

The synthesis of high-performance copper nanostructures strongly depends on the method used, where a good control over particle size, shape, and spatial distribution is of critical importance [21]. Thus, the development of new simple and low-cost processes to enhance $\mathrm{Cu}$-NPs properties is required in order to scale-up the production of $\mathrm{Cu}-\mathrm{NPs}$ at an industrial level.

Among the methods employed for the preparation of nanosized copper particles, the chemical reduction of copper(II) salts in aqueous solution is one of the most versatile routes because of its simplicity, solubility, inexpensive reagents, and short reaction times [18], allowing at the same time the possibility of controlling of $\mathrm{Cu}-\mathrm{NPs}$ sizes and shapes [2]. However, metallic copper is highly unstable as it can be easily oxidized under atmospheric conditions, generating $\mathrm{Cu}_{2} \mathrm{O}$ and/or $\mathrm{CuO}$ on the surface during and after preparation $[19,20]$. Therefore, nanoparticles must be protected adding surface-protecting stabilizing agents such as organic ligands, surfactants, or polymers that can form complexes with copper ions [17].

On the other hand, the formation of copper oxides at nanoscale can also be very useful to diverse areas [22]. Oxides 
of transition metals, especially cupric oxide $(\mathrm{CuO})$, exhibit characteristic catalytic and photocatalytic properties [23]. According to the literature, $\mathrm{Cu}(\mathrm{II}) \mathrm{O}$ is a $p$-type semiconductor compound with a monoclinic crystal structure and a narrow band gap of $1.2 \mathrm{eV}$ [24] that offers diverse applications. These include lithium ion batteries [25], magnetic storage media [26], gas sensors [27], supercapacitors [28], nanofluids [29], and antimicrobial agents [30].

The synthesis of $\mathrm{Cu}-\mathrm{NPs}$ in polymer media has several advantages compared to other agents such as their ease of processing, solubility, less toxicity, and control of nanoparticles growth [31]. Coated $\mathrm{Cu}(0)[1,32,33], \mathrm{CuO}$, and $\mathrm{Cu}_{2} \mathrm{O}$ $[23,34,35]$ nanoparticles have been obtained using different polymers as capping agents.

Generally, preformed polymeric surface stabilizers are introduced during the preparation of the metal nanoparticles; however some cases have reported the simultaneous formation of metal nanoparticles and in situ polymerization of the organic monomer $[36,37]$.

Previously in our research group we have studied the synthesis of copper nanoparticles through the wet chemical reduction method in the presence of hydrazine hydrate $\left(\mathrm{N}_{2} \mathrm{H}_{4} \cdot \mathrm{H}_{2} \mathrm{O}\right)$ as a reducing agent and nitrogen ligands allylamine (AAm), linear polyallylamine (PAAm), and partially cross-linked polyallylamine (PAAmc) as stabilizing agents [33]. The results of this study indicated the exclusive formation of $\mathrm{Cu}(0)$ nanoparticles under basic aqueous conditions in an air atmosphere. We observed that the use of small amount of monomer AAm did not affect significantly the composition of the prepared $\mathrm{Cu}(0)-\mathrm{NPs}$.

In the present study, we focus on reducing the use of expensive PAAm as a stabilizing agent in the synthesis of copper nanoparticles via chemical reduction in aqueous solution using different ratios of nitrogen ligands in mixture (AAm/PAAm/PAAmc) and with a constant concentration of $\mathrm{NaOH}$ and $\mathrm{N}_{2} \mathrm{H}_{4} \cdot \mathrm{H}_{2} \mathrm{O}$. In contrast to our previous work [33], this synthetic route gave as a result $\mathrm{Cu}(0)$ mixed with an oxidized phase of $\mathrm{CuO}$ nanoparticles.

\section{Experimental}

2.1. Materials and Reagents. Copper(II) sulfate pentahydrate, hydrazine hydrate solution (50-60\%), poly(allylamine) solution (PAAm) $(\mathrm{Mw} \sim 17000,20 \mathrm{wt} \%$ aqueous solution), allylamine (98\%), and sodium hydroxide (98.8\%) were obtained from Sigma-Aldrich and were used without previous purification. PAAmc was obtained by PAAm's warming at $40^{\circ} \mathrm{C}$ for two months. The moles of PAAm were calculated by the molecular weight of the repeating unit $\left[\mathrm{CH}_{2}-\mathrm{CH}\left(\mathrm{CH}_{2} \mathrm{NH}_{2}\right)\right]$ of $57 \mathrm{~g} / \mathrm{mol}$. Different molar ratios of nitrogen ligands/ $/ \mathrm{CuSO}_{4}$ were used. The reactions with PAAmc used higher $\mathrm{H}_{2} \mathrm{O} / \mathrm{CuSO}_{4}$ molar ratios due to the lower solubility of the ligand in $\mathrm{H}_{2} \mathrm{O}$.

2.2. Synthesis of Copper Nanoparticles. The synthesis of copper nanoparticles was performed using wet chemical reduction. In a flat bottom flask $\mathrm{CuSO}_{4} \cdot 5 \mathrm{H}_{2} \mathrm{O}$ was added, which was dissolved in distilled water under magnetic stirring for
10 minutes at $60^{\circ} \mathrm{C}$. Nitrogen ligands mixture dissolved in distilled water was then added in a dropwise manner and stirred for 10 minutes. Subsequently, a solution of $0.5 \mathrm{M}$ $\mathrm{NaOH}$ was added dropwise and allowed to react for 30 minutes followed by the addition of hydrazine. The reaction mixture was maintained at $60^{\circ} \mathrm{C}$ with constant stirring. The nanoparticles were recovered by centrifugation at $15,000 \mathrm{rpm}$ and $25^{\circ} \mathrm{C}$, purification being realized with two washes with distilled water and ethanol, and finally dried at $60^{\circ} \mathrm{C}$ for 2 hours; the NPs were obtained as black powder. The yields (R1 and R5) were calculated following our previous work [33].

2.3. Characterization Techniques. X-ray diffraction (XRD) technique was employed in order to know the oxidation state and chemical stability of the synthesized copper nanoparticles on a Siemens D-5000 diffractometer with a scanning interval in the $2 \theta$ range of 30 to $80^{\circ}$ with a scan speed of $0.02^{\circ}$ s, the radiation employed was copper $\mathrm{K} \alpha$ with a wavelength of $1.54056 \AA$, and values of $25 \mathrm{~mA}$ and $35 \mathrm{kV}$ were used for intensity and voltage, respectively. The average particle diameter was determined from the XRD diffractograms of each sample based on the Debye-Scherrer equation, taking the most intense peak for calculation $[38,39]$. Transmission electron microscopy (TEM) was used in order to observe the morphology and particle size distribution of the copper samples on a FEI Titan high-resolution electron microscope operating at $300 \mathrm{kV}$. The surface plasmon resonance (SPR) of copper nanoparticles was characterized using a UVvisible spectrophotometer (Shimadzu MultiSpec-1501) with photodiode array and a quartz cell in absorbance mode with a tungsten lamp at a wavelength of 500-800 nm.

Thermogravimetric analysis (TGA) was employed to analyze the thermal behavior of $\mathrm{Cu}$ particles and the thermal stability of coating using a DuPont Instruments 951 analyzer. Operating conditions were a heating rate of $10^{\circ} \mathrm{C} / \mathrm{min}$ and air atmosphere with a gas flow of $50 \mathrm{~mL} / \mathrm{min}$. The runs of the samples were carried out from $30^{\circ} \mathrm{C}$ to $600^{\circ} \mathrm{C}$ in $\mathrm{N}_{2}$ atmosphere. Once $600^{\circ} \mathrm{C}$ was reached $\mathrm{N}_{2}$ atmosphere was changed for $\mathrm{O}_{2} .{ }^{1} \mathrm{HNMR}$ spectra were recorded on a JEOL300 NMR spectrophotometer, in deuterated water $\left(\mathrm{D}_{2} \mathrm{O}\right)$ and using residual $\mathrm{H}_{2} \mathrm{O}$ signs as the internal reference (4.7 ppm). Infrared spectra were obtained with a Nicolet Magna 550 spectrophotometer on $\mathrm{KBr}$ crystals. Gas chromatographymass spectrometry (GS-MS) was used to study the products of thermal degradation of the coatings; the mass spectra were acquired in the GC/MS system (Agilent Technologies 7890A, 240 ion Trap) with Thermal Separation Probe (TSP) Agilent G4381A and capillary column HP-5MS. The temperature was set to from $50^{\circ} \mathrm{C}$ to $280^{\circ} \mathrm{C}$.

\section{Results and Discussion}

3.1. Effect of Nitrogen Ligands on the Synthesis of Copper Nanoparticles. The synthesis of $\mathrm{Cu}$ nanoparticles using AAm, PAAm, and PAAmc ligands with different molar ratios leads to $\mathrm{Cu}-\mathrm{NPs}$ and CuO-NPs. Table 1 shows the results obtained (R1-R5). 
TABLE 1: Results of the synthesis of copper nanoparticles by wet chemical reduction method.

\begin{tabular}{|c|c|c|c|c|c|c|}
\hline Sample & $\begin{array}{c}\text { Molar ratio of } \\
\text { PAAm } / \mathrm{Cu}\end{array}$ & $\begin{array}{c}\text { Molar ratio of } \\
\mathrm{AAm} / \mathrm{Cu}\end{array}$ & $\begin{array}{l}\text { Molar ratio of } \\
\text { AAm/PAAm }\end{array}$ & $\begin{array}{c}\text { Chemical } \\
\text { composition }^{(\mathrm{d})}\end{array}$ & $\begin{array}{c}\text { Average } \\
\text { diameter } \\
(\mathrm{nm})^{(\mathrm{d})}\end{array}$ & $\begin{array}{l}\text { Ligand } \\
(\%)\end{array}$ \\
\hline $\mathbf{R} \mathbf{1}^{\text {(a) }}$ & 0.0 & 97.0 & 0.0 & $\mathrm{Cu}^{(\mathrm{e})}$ & 30.0 & 5.6 \\
\hline $\mathbf{R} \mathbf{2}^{(\mathrm{b})}$ & 0.73 & 97.0 & 134.0 & $\mathrm{Cu}, \mathrm{CuO}$ & 15.0 & 33.6 \\
\hline $\mathbf{R 3}^{(\mathrm{b})}$ & 0.73 & 45.0 & 62.0 & $\mathrm{Cu}, \mathrm{CuO}$ & 22.0 & 24.9 \\
\hline $\mathbf{R} \mathbf{4}^{(\mathrm{c})}$ & 0.23 & 85.0 & 374.0 & $\mathrm{Cu}, \mathrm{CuO}$ & 21.0 & 12.2 \\
\hline $\mathbf{R} 5^{(c)}$ & 0.23 & 43.0 & 186.0 & $\mathrm{Cu}^{(\mathrm{f})}$ & 21.0 & 3.8 \\
\hline
\end{tabular}

(a) AAm ligand; (b) PAAmc ligand; (c) PAAm ligand; (d) determined by XRD; (e) $36 \%$ yield; (f) $70 \%$ yield.

$\mathrm{N}_{2} \mathrm{H}_{4} / \mathrm{Cu}$ molar ratio of 38.0 and a $\mathrm{NaOH} / \mathrm{Cu}$ molar ratio of 8.0.

The synthesis of $\mathrm{Cu}$ nanoparticles with PAAm and PAAmc ligands mixed with AAm (R2-R5) used AAm/PAAm molar ratios between 62 and 374 . The purpose of this study was to obtain copper nanoparticles using PAAm at lower concentrations than our previous work [33]. The data of Table 1 suggest that the ligands mixture favors the formation of $\mathrm{CuO}-\mathrm{NPs}$ and only $\mathrm{Cu}-\mathrm{NPs}$ are obtained when low concentration of AAm is used. Furthermore, the use of AAm ligand promotes $\mathrm{Cu}$ nanoparticles with higher percentage of coating. The average particle diameter is also affected by the use of AAm ligand. In order to explain the effect of AAm ligand, a detailed study was conducted on the synthesis of copper nanoparticles in the presence of this ligand.

The particle diameter $(D)$ for the indicated samples was determined by the Debye-Scherrer equation $[38,39]$ :

$$
D=\frac{0.94 \lambda}{\beta \cos \theta}
$$

where $\lambda$ is the copper wavelength (1.54056 $\AA$ ), $\theta$ is the Bragg diffraction angle, and $\beta$ is the half-width of the most intense diffraction peak. The average diameter calculated for the synthesized nanoparticles is shown in Table 1. Particles obtained with AAm/PAAm mixture show smaller particle diameters with respect to the nanoparticles obtained with AAm ligand. This suggests that polymeric ligands favor the formation of small particles and are more evident when using PAAmc.

3.2. Synthesis of Copper Nanoparticles Using AAm. In previous results of our research group we studied the synthesis of copper nanoparticles using AAm ligand. The use of this ligand led exclusively to $\mathrm{Cu}-\mathrm{NPs}$ and the isolation by centrifugation gave $36 \%$ yield (Table 1). Here, we report a more detailed study of R1. The new evidence indicates that most of the $\mathrm{Cu}$ nanoparticles remained in a wine-red colloidal solution. After a month the solution kept the same color and no precipitation was observed.

The solution containing copper nanoparticles in colloidal form was analyzed by UV-visible spectroscopy (UV-Vis). The analysis was performed in order to determine the type of copper particle in the solution. UV-Vis spectrum in Figure 1 shows an absorption band located at $\sim 566 \mathrm{~nm}$ attributed to metallic copper, which agrees with the values reported in the literature in the range of $\sim 560$ to $570 \mathrm{~nm}$ [40]. Evidence of

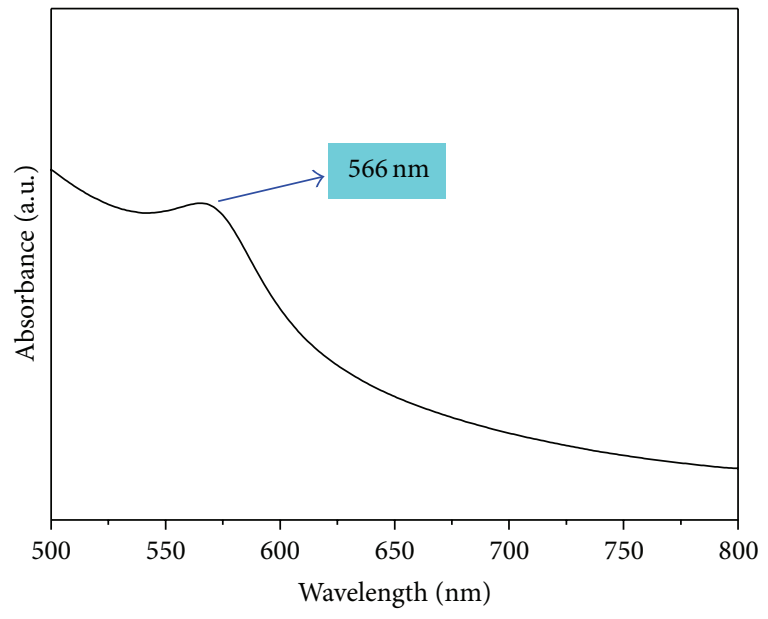

FIGURE 1: UV-Vis spectra of colloidal copper nanoparticles R1 synthesized with AAm/Cu molar ratio of 97.0.

the formation of spherical copper nanoparticles is sustained in the characteristic $\mathrm{Cu}^{0}$ plasmon peak at $566 \mathrm{~nm}$ and the red-wine color solution. It is well known that the position and shape of plasmon absorption of metal nanoparticle are strongly dependent on the particle size, dielectric medium, and surface adsorbed species [41, 42]. According to Mie's theory [43], single SPR peak was expected for spherical nanoparticles, whereas anisotropic shape particles could give two or more SPR peaks depending on the shape of the particle.

Figure 2 shows the micrograph of particles in colloidal solution, the histogram of particle size distribution, and a vial with a red colloidal solution.

According to the micrographs shown in Figure 2, monodispersed copper particles with spherical morphology can be observed. The presence of PAAm is not that clear, probably because the PAAm formed in this solution has a low molecular weight, which hinders observation; this also helps to explain the colloidal stability of the solution due to the fact that PAAm with low molecular weight is very soluble in water and can stabilize the nanoparticles better, avoiding its precipitation. The histogram behavior is closed or narrowed and exhibited an average particle diameter of $6.1 \mathrm{~nm}$. 


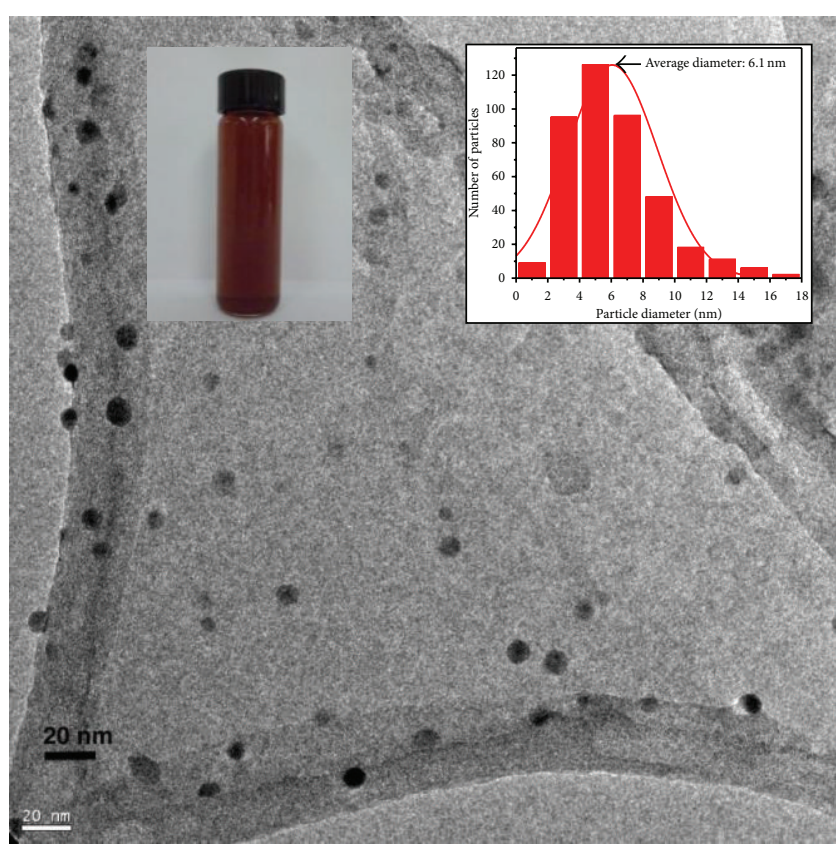

FIGURE 2: TEM micrograph of colloidal copper nanoparticles R1 synthesized with AAm/Cu molar ratio of 97.0.

The particle size distribution of this sample was obtained from the count of $\sim 400$ particles.

As previously mentioned, the colloidal solution is stable for about a month, after this time the nanoparticles start to precipitate in the aqueous medium and the solution turns pale yellow. Two drops of this solution were analyzed by proton nuclear magnetic resonance $\left({ }^{1} \mathrm{HNMR}\right)$ and the spectrum obtained in $\mathrm{D}_{2} \mathrm{O}$ presented mainly fine signals of AAm centered at $3.2 \mathrm{ppm}, 4.8 \mathrm{ppm}, 5.1 \mathrm{ppm}$, and $5.9 \mathrm{ppm}$ along with other smaller signals between 0.75 and $2.9 \mathrm{ppm}$.

To observe better the signals of PAAm formed in situ the solution was first evaporated to eliminate AAm and water where a solid was obtained. The ${ }^{1}$ HNMR spectrum (Figure 3) presented the small signals with greater clarity and the chemical shifts located at $1.0-1.6 \mathrm{ppm}$ and $2.46 \mathrm{ppm}$ are very similar to commercial PAAm. In addition, the bandwidth and the presence of multiple signals in the analyzed spectrum region suggests the presence of oligomers and/or polymers with similar chemical structures to PAAm. Clearly, the transformation of AAm monomer leads to a mixture of products with amino groups that stabilize $\mathrm{Cu}-\mathrm{NPs}$ in colloidal form.

FTIR analysis of the solid obtained after evaporation also gave evidence of the presence of PAAm. The spectrum obtained in $\mathrm{KBr}$ presented between 500 and $1900 \mathrm{~cm}^{-1}$ three very intense bands at $983 \mathrm{~cm}^{-1}, 1449 \mathrm{~cm}^{-1}$, and $1601 \mathrm{~cm}^{-1}$ (Figure 4). The FTIR spectrum of commercial PAAm also presents three intense bands located at frequencies of $938 \mathrm{~cm}^{-1}, 1450 \mathrm{~cm}^{-1}$, and $1596 \mathrm{~cm}^{-1}$. The changes in the frequencies are associated with the coordination of $\mathrm{Cu}$ nanoparticles with amino groups, and these are more evident in the vibrations of $\mathrm{N}-\mathrm{H}$ and $\mathrm{C}-\mathrm{N}$ bonds.

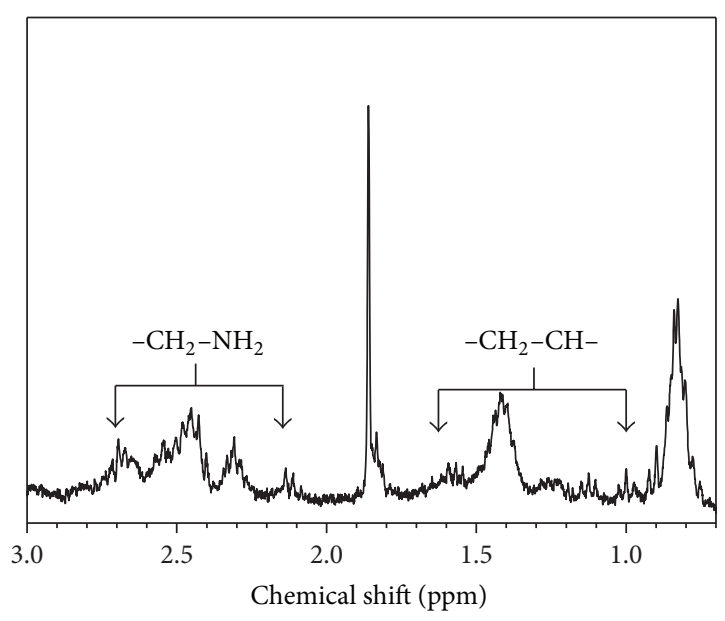

Figure 3: ${ }^{1} \mathrm{HNMR}$ of PAAm formed in situ $\left(\mathrm{D}_{2} \mathrm{O}, 25^{\circ} \mathrm{C}\right)$.

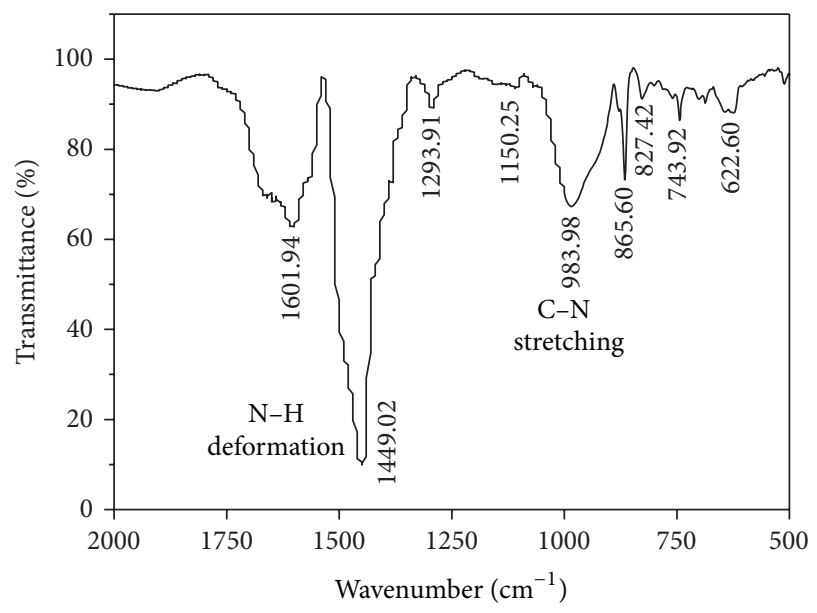

FIgURE 4: FTIR of PAAm formed in situ.

GS-MS technique was also used to analyze PAAm and coating of samples R1-R5, mass spectrum of PAAm shows peaks at $m / z=28,29,30,33,39,41,42,43,44,45$, and 57 , and these values reflect the thermal decomposition and formation of allylamine monomer located at $m / z 57$ [44]. Most of these peaks are detected in the mass spectrum of allylamine monomer and primary amines [45]. The mass spectrum of R1 presented most of these peaks suggesting that during the synthesis of nanoparticles R1 PAAm was formed. The same result was observed in samples $\mathbf{R} \mathbf{2}-\mathbf{R} \mathbf{5}$ where PAAm was used for the synthesis of copper nanoparticles.

In summary, the use of different characterization techniques suggest that during the synthesis of $\mathrm{Cu}$ nanoparticles the AAm monomer undergoes polymerization reactions, leading to an oligomer and/or polymer with a similar structure to PAAm. The in situ PAAm synthesis may be important from an economic standpoint because it could avoid using polymer PAAm, which is expensive compared to AAm. There are reports in the literature that can help to explain what happens in reaction $\mathbf{R 1}$ as it is known that $\mathrm{CuSO}_{4} / \mathrm{N}_{2} \mathrm{H}_{4}$ system is capable of initiating the polymerization of methyl 


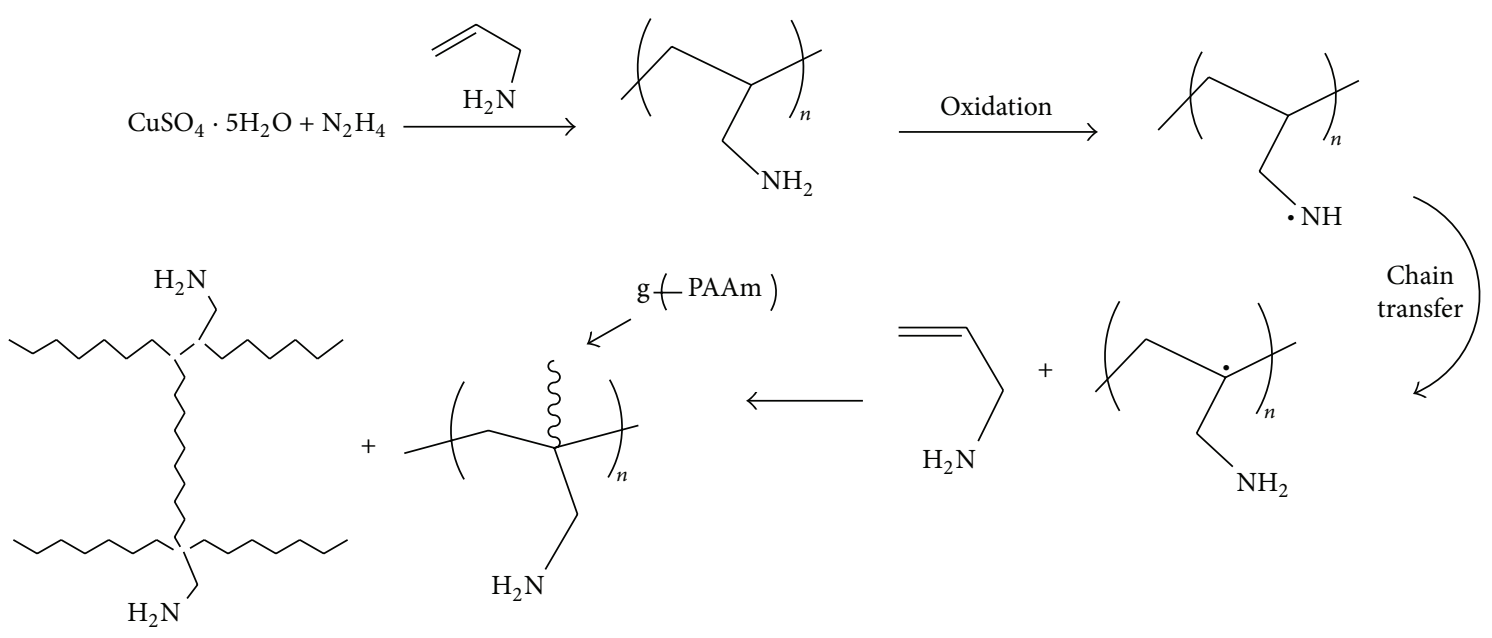

Cross-linked PAAm

Figure 5: Possible reaction mechanism of the formation of PAAm with different structures.

methacrylate in water in a basic medium [46]. The reaction conditions in R1 are very similar to those used in this report and it is likely that polymerization of AAm proceeded in the same way. Grafting and/or crosslinking reactions may also be explained as follows: once PAAm is formed the amino groups may be oxidized and form radical species on the nitrogen atom; these species are rearranged forming free radicals on the PAAm backbone, which react with AAm monomer. When the concentration of the monomer is low the recombination of the growing chains could form partially cross-linked PAAm. A similar explanation was made in the preparation of grafted copolymers PAAm-g-poly $(\mathrm{t}-$ BA) [47]. Figure 5 illustrates a possible mechanism of the polymerization of AAm and other reactions that can be performed in reaction $\mathbf{R} \mathbf{1}$.

3.3. Effect of the Content of Mixture of AAm and PAAm on the Synthesis of Copper Nanoparticles. The synthesis of copper nanoparticles was also performed using a mixture of AAm, linear polyallylamine (PAAm), and partially cross-linked polyallylamine (PAAmc). The goal was to obtain a synthesis method that enables the use of the least amount of PAAm and leads to copper nanoparticles. Reactions $\mathbf{R} 2$ and $\mathbf{R} 3$ that used AAm and PAAmc led to a mixture of $\mathrm{Cu}(0)$ and $\mathrm{CuO}$ nanoparticles; apparently a combination of these nitrogen ligands favors the oxidation of copper. In the case of reactions R4 and R5 where linear PAAm and a PAAm/Cu constant molar ratio of 0.23 were used led to a mixture of nanoparticles $(\mathrm{Cu}$ and $\mathrm{CuO})$ and $\mathrm{Cu}(0)$, respectively. Reaction $\mathbf{R} 5$ that used $\mathrm{AAm} / \mathrm{Cu}$ molar ratio of 43 suggests that it is possible to obtain copper nanoparticles without evidence of oxidation when the concentration of AAm in the reaction medium is not very high. Figure 6 shows the XRD diffractograms of nanoparticles synthetized under different AAm/PAAm molar ratios (Table 1), experiments $\mathbf{R} 2-\mathbf{R} 3$ and $\mathbf{R} 4-\mathbf{R} 5$.

The XRD diffractograms of the particles obtained show several reflections that correspond to $\mathrm{Cu}(0)$ and $\mathrm{CuO}$ NPs. A comparison with the standards shown at the bottom of

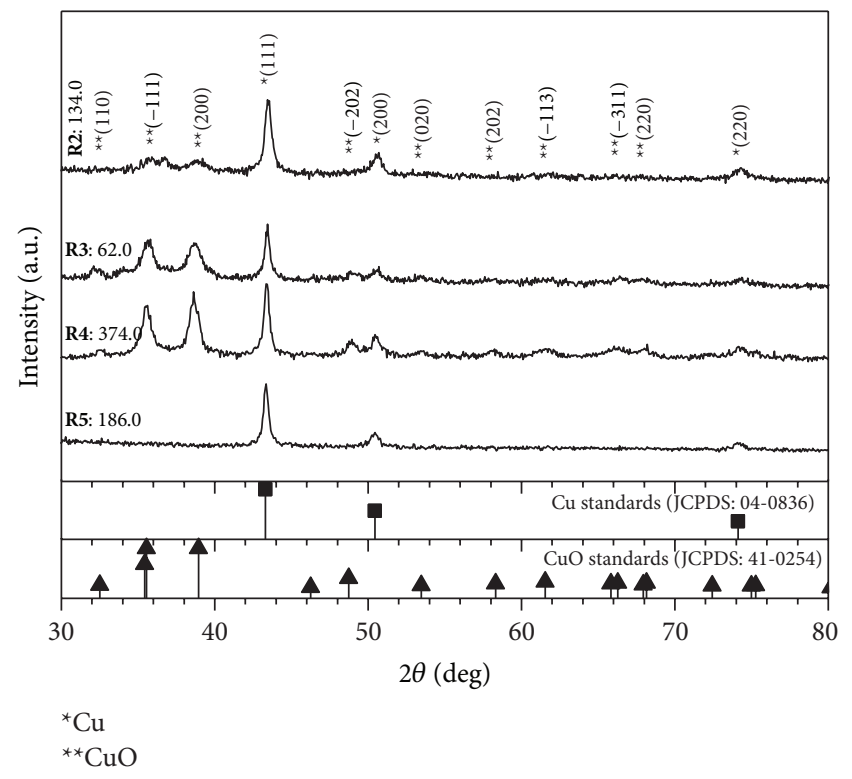

FIGURE 6: XRD diffractograms of copper nanoparticles synthesized by chemical reduction with different AAm/PAAm molar ratios.

the graph readily identifies each type of NPs and only the diffractogram obtained in NPs R5 exhibits the three properties of metallic copper reflections [48, 49]. XRD analysis indicated that the reaction conditions used in $\mathbf{R} 5$ allowed the preparation of $\mathrm{Cu}-\mathrm{NPs}$ without the presence of impurities such as $\mathrm{CuO}, \mathrm{Cu}_{2} \mathrm{O}$, and $\mathrm{Cu}(\mathrm{OH})_{2}$.

The average particle size was calculated by using the Debye-Scherrer equation [38, 39], yielding lower values than $25 \mathrm{~nm}$. The nanoparticles obtained with AAm/PAAmc mixture presented coating weight percentages between $25 \%$ and $34 \%$, while nanoparticles obtained with AAm/PAAm, identified as R4 and R5, presented $3.8 \%$ and $12.2 \%$ of coating, respectively (Table 1); the values are higher than those previously reported in reactions where linear PAAm 


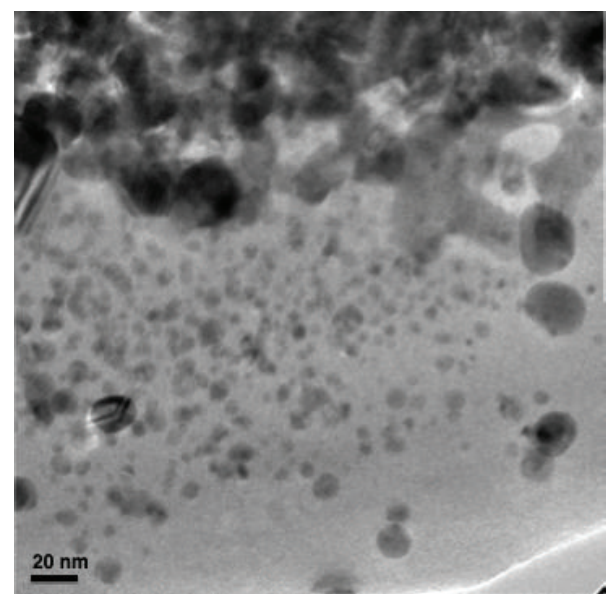

FIGURE 7: TEM micrograph of copper nanoparticles R2 synthesized by chemical reduction with AAm/PAAmc of 134.0 .

was used [33]. This data suggests that part of AAm monomer can polymerize and form part of the final coating of the nanoparticle.

Through transmission electron microscopy it was able to observe the morphology and particle size distribution of $\mathrm{Cu}$ nanoparticles R2-R5. The nanoparticles obtained with PAAmc (R2 and R3) presented spherical morphology with particle diameters between 3 and $22 \mathrm{~nm}$; both micrographs showed nanoparticles with spherical and semispherical form with well dispersed zones and others with strong agglomeration. Figure 7 shows the micrographs of the nanoparticles R2.

The analysis by TEM of nanoparticles obtained with PAAm identified as $\mathbf{R 4}$ and $\mathbf{R 5}$ indicated that the particle growth was very different. Figure 8 shows the micrograph of NPs R4. The image shows agglomerates of nanoparticles with different geometrical shapes, highlighting hemispherical subparticles with sizes of about 5 to $10 \mathrm{~nm}$ and similar structures to the shape of rods with lengths of about $50 \mathrm{~nm}$. All these particles appear to be embedded in the polymer matrix of PAAm. The presence of rod-shaped particles is favored when $\mathrm{CuO}$ is formed [50]. Other authors reported the formation of these geometries when a high concentration of PAAm is used in the synthesis [32].

The micrograph of Figure 8 also shows the patterns of selected area electron diffraction (SAED). The SAED pattern shown in the upper right part of the image exhibits mainly the diffraction of $\mathrm{CuO}-\mathrm{NPs}$ with lattice distance of $0.25,0.186$, and $0.1408 \mathrm{~nm}$ corresponding to the (002), (-202), and (-311) planes, respectively. These values were taken from the most notorious and strong diffractions of the diffractogram besides showing other diffractions that correspond to metallic $\mathrm{Cu}$ with lattice distances of 0.209 and $0.1808 \mathrm{~nm}$. On the other hand, the SAED diffraction pattern that is found at the bottom of the image on the left side displayed completely the diffractions of $\mathrm{CuO}$ with lattice distance of $0.23,0.1776$, and $0.157 \mathrm{~nm}$, corresponding to the (111), (112), and (202) planes, respectively. This is a further evidence of the formation of $\mathrm{Cu}$ NPs mixed with CuO-NPs.

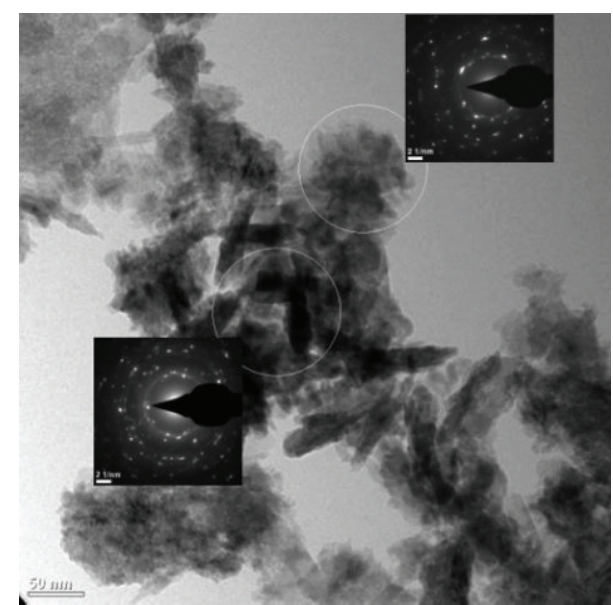

FIGURE 8: TEM micrograph of copper nanoparticles R4 synthesized by chemical reduction with AAm/PAAm molar ratio of 374.0.

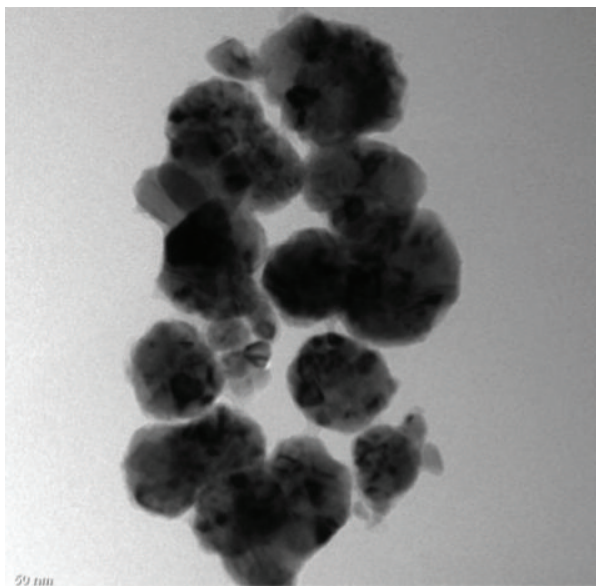

FIGURE 9: TEM micrograph of copper nanoparticles R5 synthesized through chemical reduction with AAm/PAAm molar ratio of 186.0.

Figure 9 exhibits the TEM micrograph of nanoparticles R5 synthesized with the lowest concentration of AAm. The micrograph shows agglomerates of nanosized hemispherical shapes. The agglomerates are completely covered with PAAm and within them there are subparticles with irregular morphologies (mostly hemispherical). High-resolution micrographs (not shown) presented nanoparticles covered with a PAAm shell of about $9 \mathrm{~nm}$. This polymer shell plays the role of protecting metallic copper nanoparticles against chemical oxidation and prevents agglomeration.

TEM studies in this paper indicated that nanoparticles with higher agglomeration were those synthesized using partially cross-linked PAAm and NPs that presented a high percentage of $\mathrm{CuO}$ (R3 and $\mathbf{R} 4)$.

TGA analysis of nanoparticles synthesized under different AAm/PAAm molar ratios (Table 1) of experiments R1R5 allowed us to determine the thermal behavior of the inorganic material and the polymer coating present on the NPs. Figure 10 shows the TGA thermograms of synthesized particles along with neat PAAm ligand for comparison 
TABLE 2: TGA results of copper nanoparticles obtained with mixture of ligands PAAm and AAm.

\begin{tabular}{|c|c|c|c|c|c|}
\hline Sample & AAm/PAAm & $\mathrm{Cu}(\%)$ & Ligand (\%) & $\begin{array}{c}\text { Solvent } \\
(\%)\end{array}$ & $\begin{array}{c}\text { Maximum degradation } \\
\text { temperature }\left({ }^{\circ} \mathrm{C}\right)\end{array}$ \\
\hline PAAm & 0.0 & 0.0 & 86.0 & 14.0 & $\sim 440.0$ \\
\hline R1 & 0.00 & 93.2 & 5.6 & 1.2 & $\sim 354.0$ \\
\hline $\mathbf{R} 2$ & 134.0 & 58.7 & 33.6 & 7.7 & $\sim 421.5$ \\
\hline R3 & 62.0 & 69.2 & 24.9 & 5.9 & $\sim 414.2$ \\
\hline R4 & 374.0 & 83.1 & 12.2 & 4.7 & $\sim 430.6$ \\
\hline R5 & 186.0 & 94.6 & 3.8 & 1.6 & $\sim 430.1$ \\
\hline
\end{tabular}

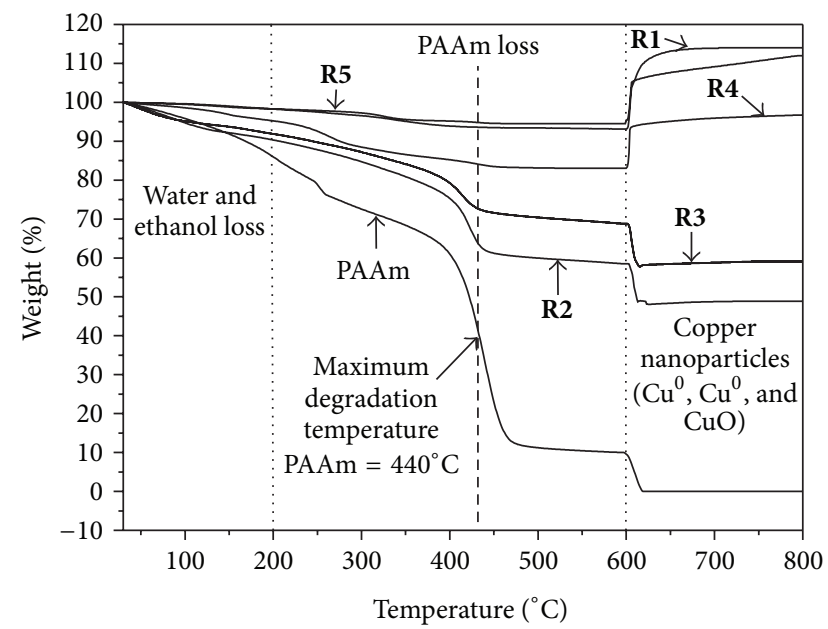

FIGURE 10: TGA thermograms of copper nanoparticles synthesized through chemical reduction with different AAm/PAAm molar ratios.

purposes. In addition, Table 2 shows the percent of coating, solvent, and inorganic material.

The thermogram of neat PAAm shows three weight-loss events; the first event is located in a temperature range of $\sim 30$ to $200^{\circ} \mathrm{C}$ and is attributed to water evaporation. The second loss is between temperatures of $\sim 200$ and $494^{\circ} \mathrm{C}$, where a marked fall is observed and is awarded to the decomposition of PAAm with a peak decomposition temperature of $440^{\circ} \mathrm{C}$; this value is very close to that reported in the literature $[51,52]$. The third and final stage of loss of material is between $600^{\circ} \mathrm{C}$ and $620^{\circ} \mathrm{C}$ and is assigned to the degradation of pyrolytic carbon from the polymer ligand due to the entrance of an oxygen source. The formation and thermal degradation of this type of coal have been reported in previous work [53].

The thermal stability of the coating is very similar to that presented by neat PAAm; the loss at low temperatures corresponds to volatiles present in the samples. Between $200^{\circ} \mathrm{C}$ and $600^{\circ} \mathrm{C}$ most of the mass of the polymer is lost. At temperatures higher than $600^{\circ} \mathrm{C}$ samples $\mathbf{R} \mathbf{2}$ and $\mathbf{R} 3$ are completely degraded and only inorganic residues remain due to the administration of $\mathrm{O}_{2}$. In the case of NPs R4 and $\mathbf{R 5}$ a gain in weight is presented after $600^{\circ} \mathrm{C}$ and it was more evident in NPs of R5, which displayed the lowest percentage of coating. The weight gain is due to the oxidation of $\mathrm{Cu}-\mathrm{NPs}$ to thermodynamically more stable $\mathrm{CuO}$ particles.
The TGA analysis performed in this research indicated that the use of partially cross-linked PAAm prevents oxidation of nanoparticles even under drastic oxidation conditions. All those nanoparticles synthesized with linear PAAm and presenting low percentages of coating did not show this thermodynamic stability. The experimental evidence suggests that nanoparticles $\mathbf{R} \mathbf{1}-\mathbf{R} \mathbf{3}$ are trapped in the polymer matrix and because the coating percentage is high the pyrolytic carbon residues could protect nanoparticles at temperatures above $600^{\circ} \mathrm{C}$.

Higher values of coated nanoparticles were those where partially cross-linked PAAm was used and corresponds to samples R2 and R3 with values of 33.6 and 24.9\%, respectively.

\section{Conclusions}

Synthesis of metallic copper particles was achieved using nitrogen ligands AAm and PAAm individually. The average particle diameters determined by XRD were lower than $31 \mathrm{~nm}$. The synthesis of copper nanoparticles in the presence of both ligands favors the formation of $\mathrm{Cu}-\mathrm{NPs}$ and $\mathrm{CuO}-\mathrm{NPs}$ nanoparticles. Pure form of $\mathrm{Cu}-\mathrm{NPs}$ was obtained only when using AAm/Cu molar ratio of 43. The use of PAAm promotes the synthesis of particles with low percentage of coating and with high yields, while the use of partially cross-linked PAAm favors the preparation of nanoparticles with a high percentage of coating and with moderate yields. In general, the use of AAm monomer in the synthesis of copper nanoparticles does not have a significant effect on the particle size; however, it may affect the yield. Despite this disadvantage, the total or partial replacement of PAAm ligand for AAm ligand in the studied synthetic method may be important from an academic and industrial perspective.

\section{Conflict of Interests}

The authors declare that there is no conflict of interests regarding the publication of this paper.

\section{Acknowledgments}

The authors gratefully acknowledge the financial support from CONACYT Grant 127151/EU 7th FP Grant 26396, CONACYT Grant 132578, and CuVito Project. R. Sierra-Avila wishes to thank CONACYT for the Scholarship no. 23415. 
Finally, the authors would like to thank A. Espinoza Muñoz, M. Lozano Estrada, M.L Guillen Cisneros, and G. Mendez Padilla for their valuable technical support.

\section{References}

[1] M. Sampath, R. Vijayan, E. Tamilarasu, A. Tamilselvan, and B. Sengottuvelan, "Green synthesis of novel jasmine bud-shaped copper nanoparticles," Journal of Nanotechnology, vol. 2014, Article ID 626523, 7 pages, 2014.

[2] J.-G. Yang, S.-H. Yang, T. Okamoto et al., "Synthesis of copper monolayer and particles at aqueous-organic interface," Surface Science, vol. 600, no. 24, pp. L318-L320, 2006.

[3] K. Judai, S. Numao, J. Nishijo, and N. Nishi, "In situ preparation and catalytic activation of copper nanoparticles from acetylide molecules," Journal of Molecular Catalysis A: Chemical, vol. 347, no. 1-2, pp. 28-33, 2011.

[4] T. M. D. Dang, T. T. T. Le, E. Fribourg-Blanc, and M. C. Dang, "Synthesis and optical properties of copper nanoparticles prepared by a chemical reduction method," Advances in Natural Sciences: Nanoscience and Nanotechnology, vol. 2, no. 1, Article ID 015009, 2011.

[5] W. Yu, H. Xie, L. Chen, and Y. Li, "Investigation on the thermal transport properties of ethylene glycol-based nanofluids containing copper nanoparticles," Powder Technology, vol. 197, no. 3, pp. 218-221, 2010.

[6] A. Ghasemi, E. Ghasemi, and E. Paimozd, "Influence of copper cations on the magnetic properties of NiCuZn ferrite nanoparticles," Journal of Magnetism and Magnetic Materials, vol. 323, no. 11, pp. 1541-1545, 2011.

[7] R. Betancourt-Galindo, P. Y. Reyes-Rodriguez, B. A. PuenteUrbina et al., "Synthesis of copper nanoparticles by thermal decomposition and their antimicrobial properties," Journal of Nanomaterials, vol. 2014, Article ID 980545, 5 pages, 2014.

[8] G. H. Chan, J. Zhao, E. M. Hicks, G. C. Schatz, and R. P. Van Duyne, "Plasmonic properties of copper nanoparticles fabricated by nanosphere lithography," Nano Letters, vol. 7, no. 7, pp. 1947-1952, 2007.

[9] Q.-L. Zhang, Z.-M. Yang, B.-J. Ding, X.-Z. Lan, and Y.-J. Guo, "Preparation of copper nanoparticles by chemical reduction method using potassium borohydride," Transactions of Nonferrous Metals Society of China, vol. 20, pp. s240-s244, 2010.

[10] P. J. Shi, H. L. Yu, H. M. Wang, and B. S. Xu, "Tribological behaviour of surface modified copper nanoparticles as lubricating additives," Physics Procedia, vol. 50, pp. 461-465, 2013.

[11] J. Garg, B. Poudel, M. Chiesa et al., "Enhanced thermal conductivity and viscosity of copper nanoparticles in ethylene glycol nanofluid," Journal of Applied Physics, vol. 103, no. 7, Article ID 074301, 2008.

[12] N. L. Pacioni, A. Pardoe, K. L. McGilvray, M. N. Chrétien, and J. C. Scaiano, "Synthesis of copper nanoparticles mediated by photogenerated free radicals: catalytic role of chloride anions," Photochemical and Photobiological Sciences, vol. 9, no. 6, pp. 766-774, 2010.

[13] B. K. Park, D. Kim, S. Jeong, J. Moon, and J. S. Kim, "Direct writing of copper conductive patterns by ink-jet printing," Thin Solid Films, vol. 515, no. 19, pp. 7706-7711, 2007.

[14] A. O. Musa, T. Akomolafe, and M. J. Carter, "Production of cuprous oxide, a solar cell material, by thermal oxidation and a study of its physical and electrical properties," Solar Energy Materials and Solar Cells, vol. 51, no. 3-4, pp. 305-316, 1998.
[15] S. A. Kumar, H.-W. Cheng, S.-M. Chen, and S.-F. Wang, "Preparation and characterization of copper nanoparticles/zinc oxide composite modified electrode and its application to glucose sensing," Materials Science and Engineering C, vol. 30, no. 1, pp. 86-91, 2010.

[16] P. Kumari and P. Majewski, "Adsorption of albumin on silica surfaces modified by silver and copper nanoparticles," Journal of Nanomaterials, vol. 2013, Article ID 839016, 7 pages, 2013.

[17] M. Abdulla-Al-Mamun, Y. Kusumoto, and M. Muruganandham, "Simple new synthesis of copper nanoparticles in water/acetonitrile mixed solvent and their characterization," Materials Letters, vol. 63, no. 23, pp. 2007-2009, 2009.

[18] P. K. Khanna, S. Gaikwad, P. V. Adhyapak, N. Singh, and R. Marimuthu, "Synthesis and characterization of copper nanoparticles," Materials Letters, vol. 61, no. 25, pp. 4711-4714, 2007.

[19] N. Luo, K. X. Liu, X. J. Li et al., "Synthesis of graphite-coated copper nanoparticles by the detonation of a copper-doped emulsion explosive," Mendeleev Communications, vol. 22, no. 5, pp. 248-249, 2012.

[20] J. Y. Seo, H. W. Kang, D. S. Jung, H. M. Lee, and S. B. Park, “Onestep synthesis of copper nanoparticles embedded in carbon composites," Materials Research Bulletin, vol. 48, no. 4, pp. 14841489, 2013.

[21] A. Kumar, A. Saxena, A. De, R. Shankar, and S. Mozumdar, "Facile synthesis of size-tunable copper and copper oxide nanoparticles using reverse microemulsions," RSC Advances, vol. 3, no. 15, pp. 5015-5021, 2013.

[22] R. K. Bortoleto-Bugs, T. Mazon, M. Tarozzo Biasoli, A. Pavani Filho, J. Willibrordus Swart, and M. Roque Bugs, "Understanding the formation of the self-assembly of colloidal copper nanoparticles by surfactant: a molecular velcro," Journal of Nanomaterials, vol. 2013, Article ID 802174, 8 pages, 2013.

[23] S. P. Meshram, P. V. Adhyapak, U. P. Mulik, and D. P. Amalnerkar, "Facile synthesis of $\mathrm{CuO}$ nanomorphs and their morphology dependent sunlight driven photocatalytic properties," Chemical Engineering Journal, vol. 204-205, pp. 158-168, 2012.

[24] S. Anandan, G.-J. Lee, and J. J. Wu, "Sonochemical synthesis of $\mathrm{CuO}$ nanostructures with different morphology," Ultrasonics Sonochemistry, vol. 19, no. 3, pp. 682-686, 2012.

[25] X. Liu, Z. Li, Q. Zhang, F. Li, and T. Kong, "Preparation of $\mathrm{CuO} / \mathrm{C}$ core-shell nanowires and its application in lithium ion batteries," Materials Letters, vol. 80, pp. 37-39, 2012.

[26] S. G. Yang, T. Li, B. X. Gu et al., "Ferromagnetism in Mn-doped CuO," Applied Physics Letters, vol. 83, no. 18, pp. 3746-3748, 2003.

[27] P. Rai, S. Jeon, C. Lee, J. Lee, and Y. Yu, "Functionalization of $\mathrm{ZnO}$ nanorods by $\mathrm{CuO}$ nanospikes for gas sensor applications," RSC Advances, vol. 4, no. 45, pp. 23604-23609, 2014.

[28] D. P. Dubal, G. S. Gund, R. Holze, and C. D. Lokhande, "Mild chemical strategy to grow micro-roses and micro-woolen like arranged $\mathrm{CuO}$ nanosheets for high performance supercapacitors," Journal of Power Sources, vol. 242, pp. 687-698, 2013.

[29] R. Manimaran, K. Palaniradja, N. Alagumurthi, S. Sendhilnathan, and J. Hussain, "Preparation and characterization of copper oxide nanofluid for heat transfer applications," Applied Nanoscience, vol. 4, no. 2, pp. 163-167, 2014.

[30] N. Ekthammathat, T. Thongtem, and S. Thongtem, "Antimicrobial activities of $\mathrm{CuO}$ films deposited on $\mathrm{Cu}$ foils by solution chemistry," Applied Surface Science, vol. 277, pp. 211-217, 2013. 
[31] M. S. Usman, N. A. Ibrahim, K. Shameli, N. Zainuddin, and W. M. Z. W. Yunus, "Copper nanoparticles mediated by chitosan: synthesis and characterization via chemical methods," Molecules, vol. 17, no. 12, pp. 14928-14936, 2012.

[32] Y. Wang and T. Asefa, "Poly(allylamine)-stabilized colloidal copper nanoparticles: synthesis, morphology, and their surfaceenhanced raman scattering properties," Langmuir, vol. 26, no. 10, pp. 7469-7474, 2010.

[33] R. Sierra-Ávila, M. Pérez-Alvarez, G. Cadenas-Pliego et al., "Synthesis of copper nanoparticles coated with nitrogen ligands," Journal of Nanomaterials, vol. 2014, Article ID 361791, 8 pages, 2014.

[34] M. Suleiman, M. Mousa, A. Hussein, B. Hammouti, T. B. Hadda, and I. Warad, "Copper(II)-oxide nanostructures: synthesis, characterizations and their applications-review," Journal of Materials and Environmental Science, vol. 4, no. 5, pp. 792797, 2013.

[35] P. Abdulkin, Y. Moglie, B. R. Knappett et al., "New routes to $\mathrm{Cu}(\mathrm{I}) / \mathrm{Cu}$ nanocatalysts for the multicomponent click synthesis of 1,2,3-triazoles," Nanoscale, vol. 5, no. 1, pp. 342-350, 2013.

[36] J.-F. Zhu and Y.-J. Zhu, "Microwave-assisted one-step synthesis of polyacrylamide-metal $(\mathrm{M}=\mathrm{Ag}, \mathrm{Pt}, \mathrm{Cu})$ nanocomposites in ethylene glycol," Journal of Physical Chemistry B, vol. 110, no. 17, pp. 8593-8597, 2006.

[37] G. I. Dzhardimalieva, A. D. Pomogailo, N. D. Golubeva et al., "Metal-containing nanoparticles with core-polymer shell structure," Colloid Journal, vol. 73, no. 4, pp. 458-466, 2011.

[38] J. I. Langford and A. J. Wilson, "Scherrer after sixty years: a survey and some new results in the determination of crystallite size," Journal of Applied Crystallography, vol. 11, no. 2, pp. 102113, 1978.

[39] A. Monshi, M. R. Foroughi, and M. R. Monshi, "Modified Scherrer equation to estimate more accurately nano-crystallite size using XRD," World Journal of Nano Science and Engineering, vol. 2, no. 3, pp. 154-160, 2012.

[40] T. M. D. Dang, T. T. T. Le, E. Fribourg-Blanc, and M. C. Dang, "The influence of solvents and surfactants on the preparation of copper nanoparticles by a chemical eduction method," Advances in Natural Sciences: Nanoscience and Nanotechnology, vol. 2, no. 2, Article ID 025004, 2011.

[41] U. Kreibig and M. Vollmer, Optical Properties of Metal Clusters, Springer, Berlin, Germany, 1995.

[42] P. Mulvaney, "Surface plasmon spectroscopy of nanosized metal particles," Langmuir, vol. 12, no. 3, pp. 788-800, 1996.

[43] G. Mie, "Beiträge zur Optik trüber Medien, speziell kolloidaler Metallösungen," Annals of Physics, vol. 25, pp. 377-445, 1908.

[44] L. Denis, D. Cossement, T. Godfroid et al., "Synthesis of allylamine plasma polymer films: correlation between plasma diagnostic and film characteristics," Plasma Processes and Polymers, vol. 6, no. 3, pp. 199-208, 2009.

[45] H. Budzikiewicz, C. Djerassi, and H. Dudley, Interpretation of Mass Spectra of Organic Compounds, Holden Day, San Francisco, Calif, USA, 1964.

[46] J. Bond and P. Lee, "The cupric sulfate-hydrazine systems as an initiator of vinyl polymerization. The polymerization of methyl methacrylate in aqueous solution in the presence of oxygen," Journal of Polymer Science, vol. 7, pp. 379-385, 1969.

[47] D. Sarkar, J. M. El Khoury, S. T. Lopina, and J. Hu, "Grafting poly(t-butyl acrylate) to poly(allylamine) by inverse microemulsion radical polymerization: from comb-polymer to amphiphilic shell crosslinked polymer nanocapsule," Journal of Applied Polymer Science, vol. 104, no. 3, pp. 1905-1911, 2007.
[48] O. Mondal, A. Datta, D. Chakravorty, and M. Pal, "Ultrafine narrow dispersed copper nanoparticles synthesized by a facile chemical reduction method," MRS Communications, vol. 3, no. 02, pp. 91-95, 2013.

[49] S. V. Saikova, S. A. Vorob’ev, R. B. Nikolaeva, and Y. L. Mikhlin, "Conditions for the formation of copper nanoparticles by reduction of copper(II) ions with hydrazine hydrate solutions," Russian Journal of General Chemistry, vol. 80, no. 6, pp. 11221127, 2010.

[50] D. P. Singh, A. K. Ojha, and O. N. Srivastava, "Synthesis of different $\mathrm{Cu}(\mathrm{OH})_{2}$ and $\mathrm{CuO}$ (nanowires, rectangles, seed-, belt-, and sheetlike) nanostructures by simple wet chemical route," Journal of Physical Chemistry C, vol. 113, no. 9, pp. 3409-3418, 2009.

[51] J. M. El Khoury, D. Caruntu, C. J. O’Connor, K.-U. Jeong, S. Z. D. Cheng, and J. Hu, "Poly(allylamine) stabilized iron oxide magnetic nanoparticles," Journal of Nanoparticle Research, vol. 9, no. 5, pp. 959-964, 2007.

[52] S. J. Kim, S. J. Park, M.-S. Shin, Y. H. Lee, N. G. Kim, and S. I. Kim, "Thermal characteristics of IPNs composed of polyallylamine and chitosan," Journal of Applied Polymer Science, vol. 85, no. 9, pp. 1956-1960, 2002.

[53] J. Rodriguez-Mirasol, T. Cordero, L. R. Radovic, and J. J. Rodriguez, "Structural and textural properties of pyrolytic carbon formed within a microporous zeolite template," Chemistry of Materials, vol. 10, no. 2, pp. 550-558, 1998. 

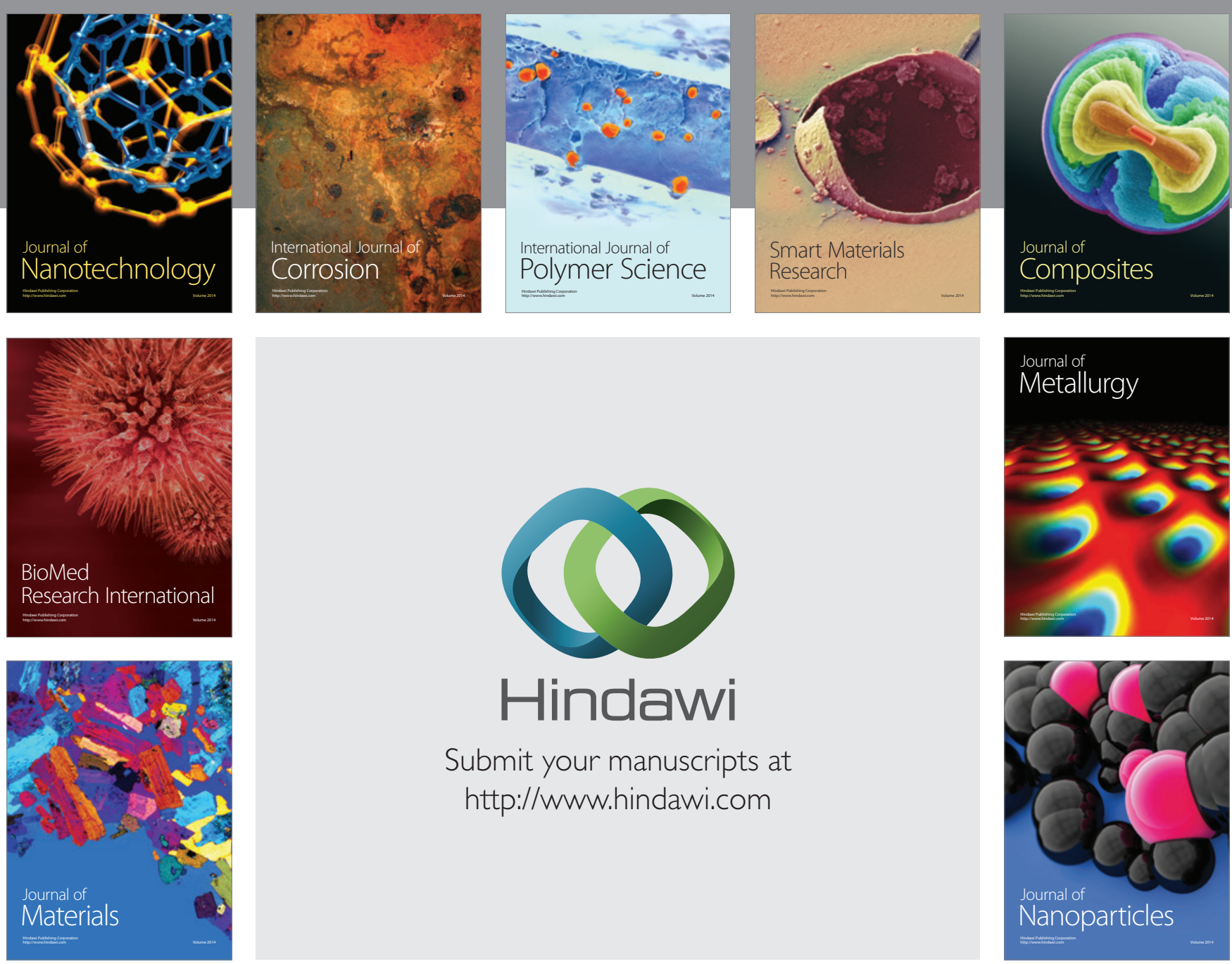

Submit your manuscripts at http://www.hindawi.com
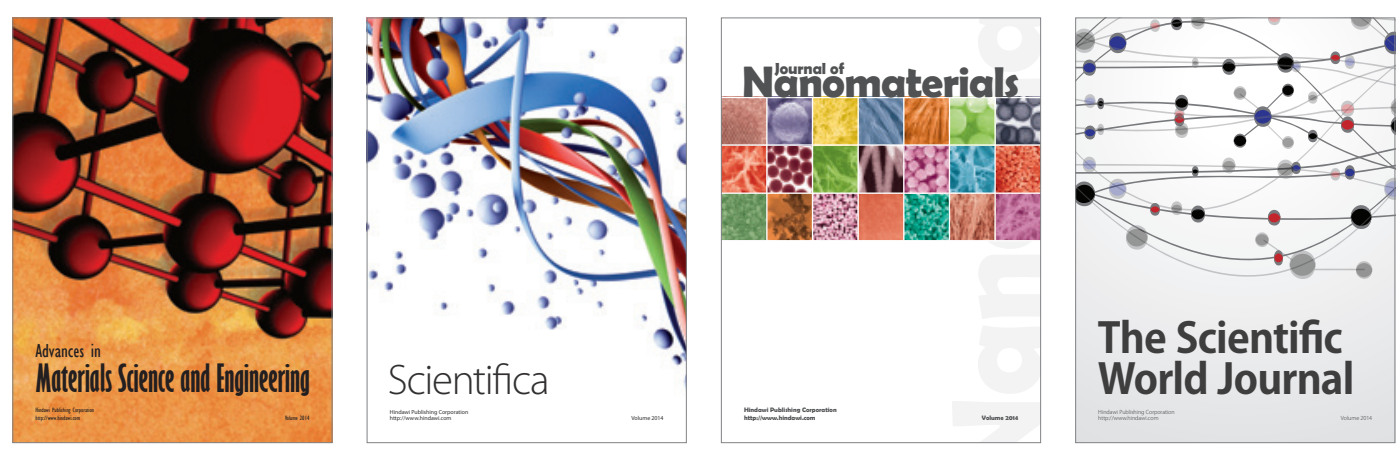

\section{The Scientific World Journal}
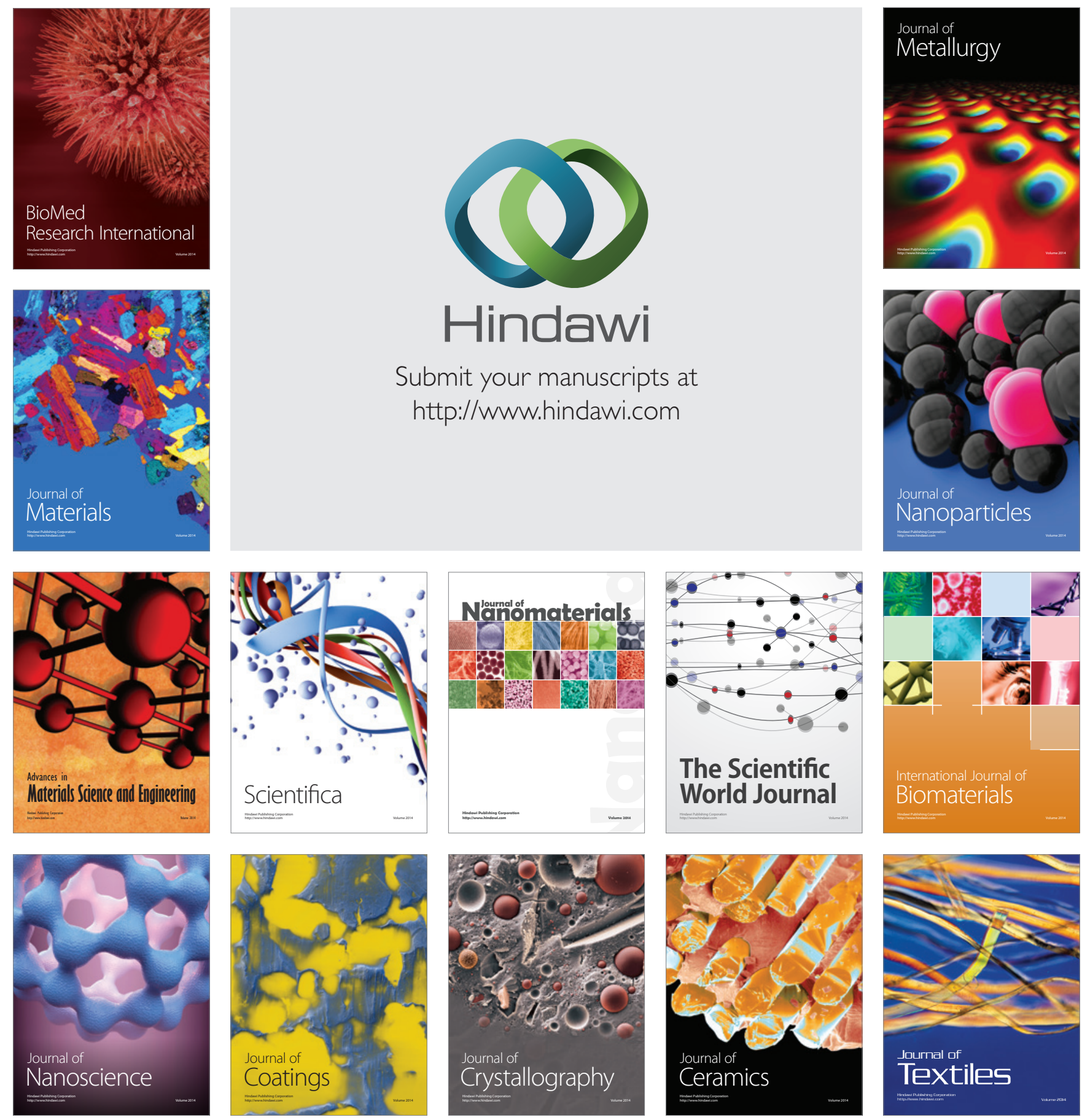